\title{
Perspectives of Asian Employers on Graduates' Soft Skills: A Systematic Review
}

\author{
Afifah Hanim Md Pazil*, Razli Che Razak \\ Faculty of Entrepreneurship and Business, Universiti Malaysia Kelantan, Malaysia \\ Received September 7, 2019; Revised October 10, 2019; Accepted October 17, 2019
}

Copyright $@ 2019$ by authors, all rights reserved. Authors agree that this article remains permanently open access under the terms of the Creative Commons Attribution License 4.0 International License

\begin{abstract}
At present, the situation of the economic world is very challenging. As such employers are looking for versatile graduates, who will be able to drive the organisations so that they can compete successfully in the market place. Graduates nowadays are expected by the employers to not only obtain good degrees and excel in their academics, but also to equip themselves with soft skills. Globalisation means increasing integration of various sectors in today's world and leads to a demand for higher level graduates' soft skills. By adopting a systematic literature review approach, the current study attempts to present an exploration of the employers' perspectives on the soft skills needed by graduates to be developed to get them ready for the job place. The review was guided by the PRISMA Statement (Preferred Reporting Items for Systematic reviews and Meta-Analyses). A systematic literature search was undertaken from two main journal databases - Scopus and Web of Science (WoS). All papers reviewed from articles published from 2010 to 2019. Based on the search results, the literature was synthesised, and the varied soft skills were classified into 11 major domains. The contribution of the current study can be seen as the classification of the varied graduates' soft skills. It can provide insightful information to the stakeholders of higher education institutions. To produce job-ready graduates, higher education institutions need to re-evaluate their teaching and learning approaches to develop the necessary graduates' soft skills as needed by the job market.
\end{abstract}

Keywords Soft Skills, Graduate, Employers' Perspectives, Asian

\section{Introduction}

It is certainly cannot be denied that the quality of graduates play a key role in the growth and development of a highly-income developed nation. The quality of graduates can be enriched with the high quality of education provided by the higher education institutions. The higher education institutions should have a system that is market-driven and able to produce job-ready graduates. However, producing job-ready graduates is one of the important challenges faced by higher education institutions worldwide (Kostenkova et al., 2016; Natalia et al., 2015). Some critics contend that graduates from higher education institutions are unable to meet the employers' expectations and relevant job requirements in today's ever changing economic environment (Kahirol et al., 2016; Rohani et al., 2016; Kalaivani et al., 2012; Rahmah et al., 2011; Salina et al., 2011a; Salina et al., 2011b). Employers nowadays are seeking those who have both the appropriate academic qualifications and are highly skilled who are able to compete successfully in the market (Shiau et al., 2018; Kalaivani et al., 2012; Rahmah et al., 2011; Salina et al., 2011a; Salina et al., 2011b). Many graduates do not have the right combination of excellent academic qualifications and highly skilled as required by employers. As a result, they are unable to secure the employment which subsequently contributes to an alarming of a high graduate unemployment rate (Kahirol et al., 2016; Kalaivani et al., 2012; Noor Azina, 2011; Salina et al., 2011a).

Scholars have attempted to classify skills into two categories, 'hard skills' and 'soft skills'. Hard skills are those related to the technical aspects of acquiring the knowledge to perform a job (Matsouka \& Mihail, 2016). Soft skills are those connected with personal interaction and are behavioural (Andrews \& Higson, 2008). Employers require graduates to have the hard skills necessary for their specific professions (Low et al., 2016). However, beyond that, studies have found that soft skills are more important because it has been receiving greater attention in organisations and are in higher demand by employers (Dunbar et al., 2016; Kahirol et al., 2016; Stewart et al., 2016). The terminology used to refer to soft skills is plentiful. The term soft skills have been described in many ways, such as generic skills, transferable skills, 
employability skills, key skills, core skills, essential skills, basic skills, personal skills, common skills, indispensable skills (Khan, 2018; Tsai, 2017; Kahirol et al., 2016; Rohani et al., 2016; Radhakrishnan \& Sudha, 2015).

Although there is an availability of studies on graduates' soft skills, most of them have only focused on a few aspects of the issue. Most of the studies have tended to evaluate the competency of the graduates in specific programmes such as Information Systems (Lavy \& Rashkovits, 2019), Music (Eğilmez et al., 2019), Accounting (Erlane et al., 2018; Dunbar et al., 2016; Low et al., 2016), Business (Abbasi et al., 2018; Jackson \& Chapman, 2012), Tourism (Tsai, 2017; Dhiman, 2012), Architecture (Rohani et al., 2016), Engineering (Triyono et al., 2018; Radhakrishnan \& Sudha, 2015; Mohd Shamsuri \& Izaidin, 2014; Mohd Shamsuri et al., 2013) and Information and Communication Technology (Mohd Shamsuri \& Izaidin, 2014; Mohd Shamsuri et al., 2013). Other than that, some of the studies focused on the specific institutions (Jeong \& Sung, 2019; Kalaivani et al., 2012) or specific regions (Khan, 2018; Triyono et al., 2018; Ting et al., 2017; Kahirol et al., 2016; Jackson \& Chapman, 2012; Rahmah et al., 2011; Roselina, 2009; Andrews \& Higson, 2008). While some of the studies only highlighted the graduates' soft skills in specific sectors such as industry (Khan, 2018; Kahirol et al., 2016), manufacturing (Shiau et al., 2018), banking (Abbasi et al., 2018) and service (Rahmah et al., 2011). Focusing on a few aspects of the issue creates a limitation in the interpretation and application of these studies across multiple organisations and regions.

Despite the abundance of studies on graduates' soft skills in specific graduates' programmes, institutions, regions or sectors, efforts to systematically review these studies are still lacking. Therefore, a systematic literature review was used for this study to present an exploration of the existing soft skills needed by graduates to be developed to get them ready for the job place. A systematic review is an examination of a formulated question that uses systematic and explicit methods to identify, select and critically appraise relevant research and to collect and analyse data from studies that are included in the review (Hayrol Azril et al., 2018). Graduates can be defined as students who have passed and completed their study at the end of their academic session. This study attempts to fill the gap in identifying and classifying the existing graduates' soft skills from the perspective of Asian employers.

\section{Methodology}

In this section, the method used to retrieve articles related to graduates' soft skills from the perspective of Asian employers is discussed. The systematic literature review was guided by the PRISMA Statement (Preferred Reporting Items for Systematic reviews and Meta-Analyses). The PRISMA Statement allows for a rigorous search of terms related to graduates' soft skills. The systematic literature search was undertaken from two main journal databases - Scopus and Web of Science (WoS). Scopus is one of the largest abstract and citation databases of peer-reviewed literature curated from 5,000 publishers worldwide with more than 22,800 journals. WoS is a robust database consisting of more than 18,000 high impact journals with over 100 years of comprehensive coverage.

There are four stages involved in the systematic review process. The review process was performed in April 2019. The first phase identifies keywords used for the search process. Keywords similar and related to graduates, soft skills and employers' perspectives were used based on previous studies and thesaurus (Table 1). At this stage, after careful screening, 61 duplicated articles were removed. 
Table 1. The search string used for the systematic process

\begin{tabular}{|c|c|}
\hline Databases & Keywords used \\
\hline Scopus & 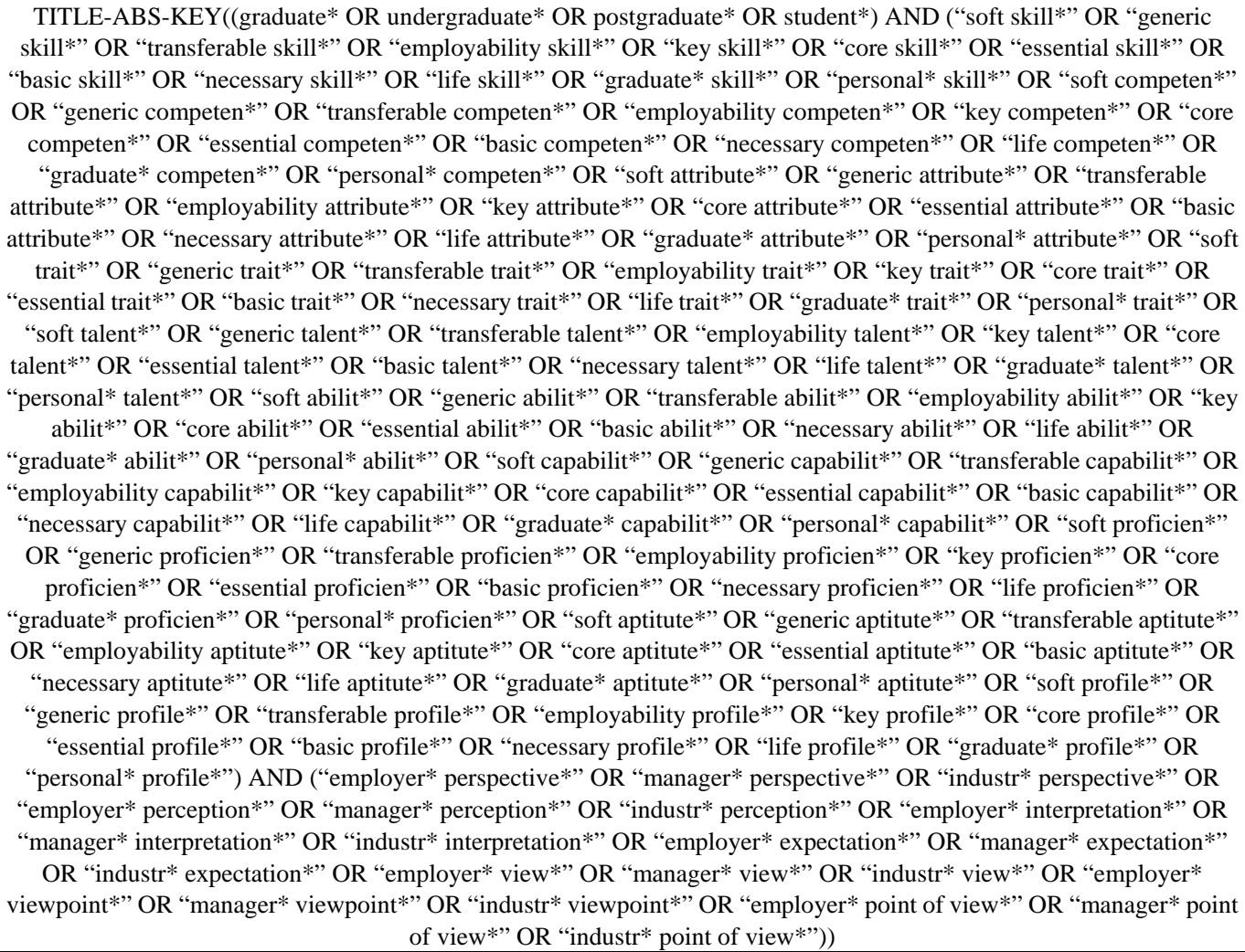 \\
\hline $\begin{array}{l}\text { Web of } \\
\text { Science }\end{array}$ & 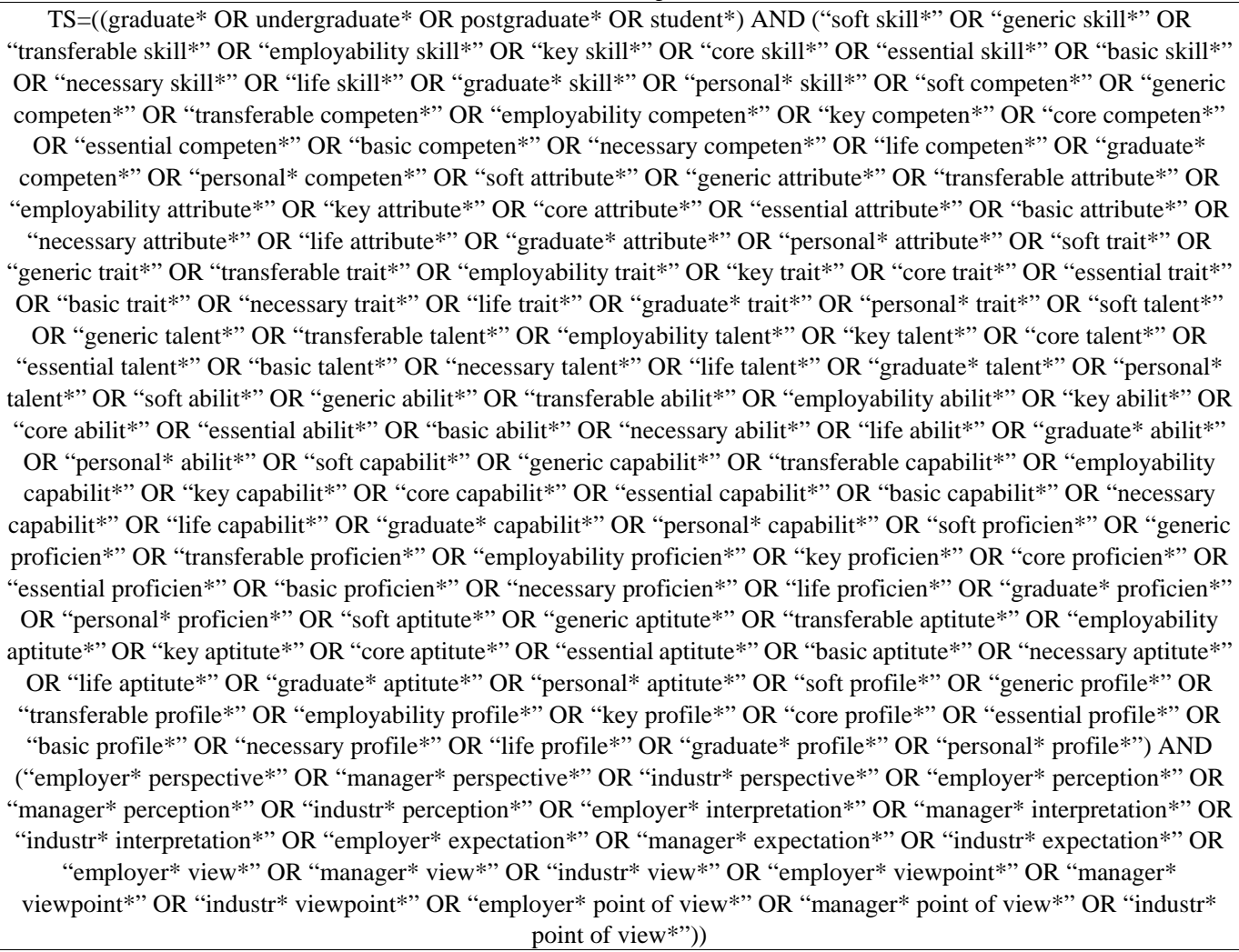 \\
\hline
\end{tabular}


The second stage was screening. At this stage, out of 217 articles eligible to be reviewed, a total of 171 were removed. As depicted in Table 2, several inclusion and exclusion criterion are determined. Firstly, about the timeline, a period of ten years are selected (between 2010 and 2019), an adequate period to see the evolution of existing studies and related publication. Secondly, with regards to the literature type, only article journals are selected, which means review article, book, book series, chapter in the book, conference proceeding and reports are all excluded. Thirdly, to avoid any confusion and difficulty in translating, the searching efforts excluded the non-English publication and focused only on articles published in English. Finally, in line with its objective, which focuses on Asian employers, only articles focused on Asian territories are selected.

The third stage is eligibility, where the 46 full articles were accessed. After careful examination, a total of 25 articles were excluded as some did not focus on employers' perspectives, were not empirical data, did not focus on the Asian region or were non-English publications. The final stage of systematic review resulted in a total of 21 articles that were used for the assessment and analysis (Figure 1). The data were extracted by reading through the abstracts, then the full articles (in-depth) to identify and classify the appropriate major domains related to graduates' soft skills.

Table 2. The inclusion and exclusion criteria

\begin{tabular}{|c|c|c|}
\hline Criteria & Inclusion & Exclusion \\
\hline Timeline & $\begin{array}{c}\text { Between 2010 } \\
\text { and 2019 }\end{array}$ & $<2010$ \\
\hline $\begin{array}{c}\text { Literature } \\
\text { Type }\end{array}$ & $\begin{array}{c}\text { Journal (research } \\
\text { articles) }\end{array}$ & $\begin{array}{c}\text { Journal (systematic review), } \\
\text { book, book series, chapter in the } \\
\text { book, conference proceeding, } \\
\text { reports }\end{array}$ \\
\hline Language & English & Non-English \\
\hline Country & Asian countries & Non-Asian countries \\
\hline
\end{tabular}

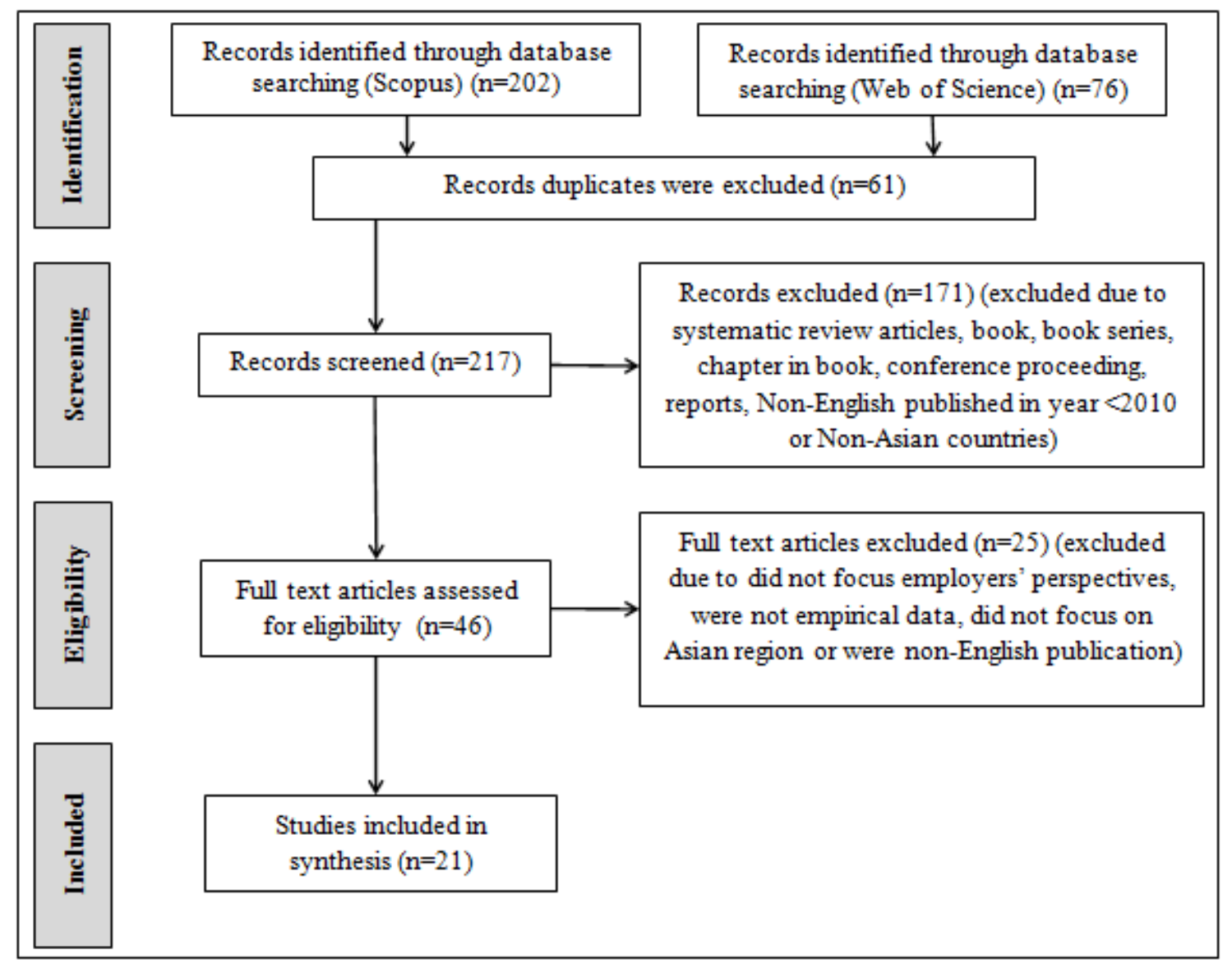

Figure 1. The flow diagram of the systematic review process of the study (Adapted from Moher et al., 2009) 


\section{Classifications and Analyses}

A total of 21 peer reviewed journal articles with reported graduates' soft skills from the perspectives of Asian employers were included in this review. Each journal articles was classified according to the publication year, country of origin, main study design, employment sector and classification of graduates' soft skills.

Figure 2 shows year-wise distribution of the 21 peer reviewed journal articles. It is expected that the number of articles in 2019 will be increase. This is because the review process was performed in April 2019 (see methodology on page 2) and not till December 2019.

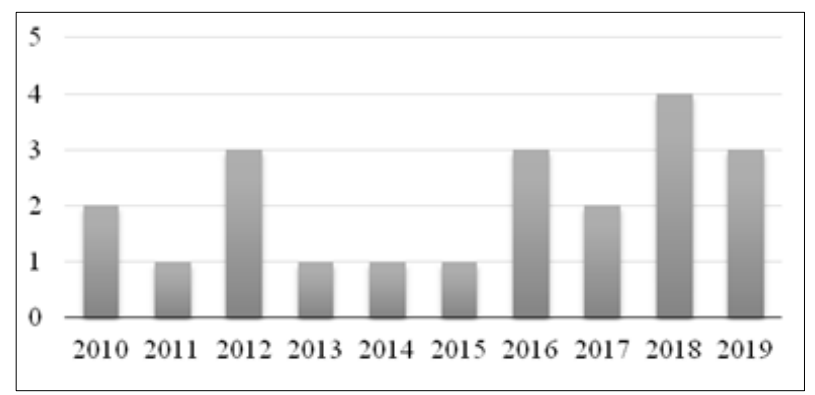

Figure 2. Distribution of 21 review journal articles in 2010-2019

Table 3 classifies reviewed journal articles by country of origin. Among the 21 journal articles considered in this systematic review, Malaysia had the largest number of published journal articles with a total of 12 studies (Siti Zaidah et al., 2019; Erlane et al., 2018; Shiau et al., 2018; Ting et al., 2017; Rohani et al., 2016; Amar Hisham et al., 2016; Kahirol et al., 2016; Mohd Shamsuri \& Izaidin, 2014; Mohd Shamsuri et al., 2013; Sivapalan et al., 2012; Kalaivani et al., 2012; Rahmah et al., 2011). This followed by three studies concentrated on employers' perspective in India (Radhakrishnan \& Sudha, 2015; Dhiman, 2012; Wickramasinghe \& Perera, 2010), two studies focused on Taiwan employers' perspective (Tsai, 2017; Lin et al., 2010), one study concentrated on employers' perspective in Hong Kong (Pang et al., 2019), one study focused on Israel employers’ perspective (Lavy \& Rashkovits, 2019), one study concentrated on employers' perspective in Saudi (Khan, 2018) and one study focused on Pakistan employers’ perspective (Abbasi et al., 2018).
Table 3. Classification of 21 review journal articles by country

\begin{tabular}{|c|c|c|}
\hline No. & Country & Number of articles \\
\hline 1 & Malaysia & 12 \\
\hline 2 & India & 3 \\
\hline 3 & Taiwan & 2 \\
\hline 4 & Hong Kong & 1 \\
\hline 5. & Israel & 1 \\
\hline 6. & Saudi & 1 \\
\hline 7. & Pakistan & 1 \\
\hline
\end{tabular}

Figure 3 illustrates main study design of the 21 reviewed journal articles. It can be seen a total of 15 studies (71\%) applied a quantitative approach, four studies (19\%) employed qualitative approaches and the remaining two studies (10\%) used mixed methods (quantitative and qualitative) approach.

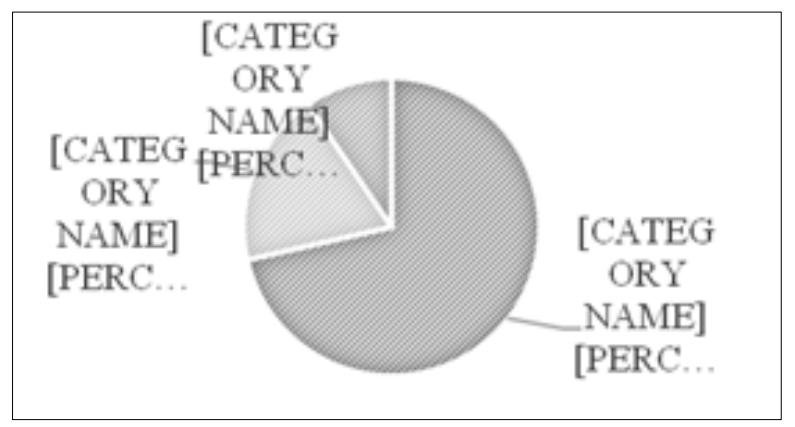

Figure 3. Main study design of 21 review journal articles

For the employment sector, the review resulted in 14 main sectors, as in Table 4. The 14 main sectors are Agricultural Industry (AI), Construction Industry (CI), Financial Institution (FI), Healthcare Industry (HI), Logistics Industry (LI), Manufacturing Industry (MI), Services Industry (SI), Technology Based (TB), Telecommunications Industry (TeI), Tourism Industry (ToI), Government Agency (GA), Government-Linked Company (GLC), Multinational Company (MNC), and Small and Medium Enterprise (SME). Among the 21 journal articles considered in this systematic review, Manufacturing Industry had the largest number of employment sector with a total of 8 studies. 
Table 4. Employment sector of 21 review journal articles

\begin{tabular}{|c|c|c|c|c|c|c|c|c|c|c|c|c|c|c|}
\hline Authors & AI & CI & FI & HI & LI & MI & SI & TB & TeI & ToI & GA & GLC & MNC & SME \\
\hline Pang et al. (2019) & & $\sqrt{ }$ & $\sqrt{ }$ & & $\sqrt{ }$ & $\sqrt{ }$ & $\sqrt{ }$ & $\sqrt{ }$ & $\sqrt{ }$ & $\sqrt{ }$ & $\sqrt{ }$ & & & \\
\hline Siti Zaidah et al. (2019) & & & & & & & & & & & $\sqrt{ }$ & $\sqrt{ }$ & $\sqrt{ }$ & $\sqrt{ }$ \\
\hline Lavy \& Rashkovits (2019) & & & & & & $\sqrt{ }$ & & $\sqrt{ }$ & & & & & \\
\hline Khan (2018) & & & & & & $\sqrt{ }$ & $\sqrt{ }$ & & & & & & & \\
\hline Erlane et al. (2018) & & & & & & & & & & & $\sqrt{ }$ & $\sqrt{ }$ & $\sqrt{ }$ & $\sqrt{ }$ \\
\hline Shiau et al. (2018) & & & & & & $\sqrt{ }$ & & & & & & & & \\
\hline Abbasi et al. (2018) & & & $\sqrt{ }$ & & & & & & & & & & & \\
\hline Tsai (2017) & & & & & & & & & & $\sqrt{ }$ & & & & \\
\hline Ting et al. (2017) & & $\sqrt{ }$ & $\sqrt{ }$ & $\sqrt{ }$ & & & & $\sqrt{ }$ & $\sqrt{ }$ & & & & & \\
\hline Rohani et al. (2016) & & $\sqrt{ }$ & & & & & & & & & & & & \\
\hline Amar Hisham et al. (2016) & & & & & & $\sqrt{ }$ & $\sqrt{ }$ & & & & & & & \\
\hline Kahirol et al. (2016) & & $\sqrt{ }$ & & & & $\sqrt{ }$ & & & & & & & & \\
\hline Radhakrishnan \& Sudha (2015) & & & & & & $\sqrt{ }$ & & & & & & & & \\
\hline Mohd Shamsuri \& Izaidin (2014) & & & & & & & & & & & $\sqrt{ }$ & $\sqrt{ }$ & $\sqrt{ }$ & $\sqrt{ }$ \\
\hline Mohd Shamsuri et al. (2013) & & & & & & & & & & & $\sqrt{ }$ & $\sqrt{ }$ & $\sqrt{ }$ & $\sqrt{ }$ \\
\hline Sivapalan et al. (2012) & & & & & & & & & & & $\sqrt{ }$ & & & \\
\hline Dhiman (2012) & & & & & & & & & & $\sqrt{ }$ & & & \\
\hline Kalaivani et al. (2012) & $\sqrt{ }$ & & & $\sqrt{ }$ & & $\sqrt{ }$ & $\sqrt{ }$ & $\sqrt{ }$ & & & & & \\
\hline Rahmah et al. (2011) & & & & & & $\sqrt{ }$ & & & & $\sqrt{ }$ & $\sqrt{ }$ & $\sqrt{ }$ & $\sqrt{ }$ \\
\hline Wickramasinghe \& Perera (2010) & & & & & & & & $\sqrt{ }$ & & & & & \\
\hline Lin et al. (2010) & & & & & & & & $\sqrt{ }$ & & & & & \\
\hline
\end{tabular}

As from the Table 5 below, the review resulted in 11 major domains related to graduates' soft skills. The 11 major domains are communication skills (CS), entrepreneurial skills (ES), interpersonal skills (IS), lifelong learning skills (LLS), management skills (MS), numeracy skills (NS), problem solving skills (PSS), professional ethics and moral skills (PEMS), self-management skills (SMS), technological skills (TeS), and thinking skills (ThS).

Table 5. The systematic review findings

\begin{tabular}{|c|c|c|c|c|c|c|c|c|c|c|c|}
\hline Authors & CS & ES & IS & LLS & MS & NS & PSS & PEMS & SMS & TeS & ThS \\
\hline Pang et al. (2019) & $\sqrt{ }$ & & $\sqrt{ }$ & $\sqrt{ }$ & & & & & $\sqrt{ }$ & \\
\hline Siti Zaidah et al. (2019) & $\sqrt{ }$ & & & & & & & & $\sqrt{ }$ & \\
\hline Lavy \& Rashkovits (2019) & $\sqrt{ }$ & $\sqrt{ }$ & $\sqrt{ }$ & $\sqrt{ }$ & $\sqrt{ }$ & & $\sqrt{ }$ & & & \\
\hline Khan (2018) & $\sqrt{ }$ & & $\sqrt{ }$ & & $\sqrt{ }$ & & & & $\sqrt{ }$ & $\sqrt{ }$ \\
\hline Erlane et al. (2018) & $\sqrt{ }$ & $\sqrt{ }$ & $\sqrt{ }$ & $\sqrt{ }$ & $\sqrt{ }$ & & $\sqrt{ }$ & $\sqrt{ }$ & & $\sqrt{ }$ & $\sqrt{ }$ \\
\hline Shiau et al. (2018) & $\sqrt{ }$ & & $\sqrt{ }$ & & & & $\sqrt{ }$ & & $\sqrt{ }$ & & \\
\hline Abbasi et al. (2018) & $\sqrt{ }$ & & $\sqrt{ }$ & & $\sqrt{ }$ & $\sqrt{ }$ & $\sqrt{ }$ & & $\sqrt{ }$ & $\sqrt{ }$ & $\sqrt{ }$ \\
\hline Tsai (2017) & $\sqrt{ }$ & & $\sqrt{ }$ & & & & & & & & \\
\hline Ting et al. (2017) & $\sqrt{ }$ & & & & & & & & & & \\
\hline Rohani et al. (2016) & & & $\sqrt{ }$ & & $\sqrt{ }$ & & $\sqrt{ }$ & & $\sqrt{ }$ & & $\sqrt{ }$ \\
\hline Amar Hisham et al. (2016) & $\sqrt{ }$ & & $\sqrt{ }$ & & $\sqrt{ }$ & & & & & $\sqrt{ }$ & $\sqrt{ }$ \\
\hline Kahirol et al. (2016) & $\sqrt{ }$ & $\sqrt{ }$ & $\sqrt{ }$ & $\sqrt{ }$ & $\sqrt{ }$ & & $\sqrt{ }$ & $\sqrt{ }$ & $\sqrt{ }$ & $\sqrt{ }$ & $\sqrt{ }$ \\
\hline Radhakrishnan \& Sudha (2015) & & & $\sqrt{ }$ & & & & $\sqrt{ }$ & & $\sqrt{ }$ & \\
\hline Mohd Shamsuri \& Izaidin (2014) & $\sqrt{ }$ & & $\sqrt{ }$ & $\sqrt{ }$ & & & $\sqrt{ }$ & & & $\sqrt{ }$ & \\
\hline Mohd Shamsuri et al. (2013) & $\sqrt{ }$ & & $\sqrt{ }$ & $\sqrt{ }$ & & & $\sqrt{ }$ & & & $\sqrt{ }$ & \\
\hline Sivapalan et al. (2012) & $\sqrt{ }$ & & $\sqrt{ }$ & $\sqrt{ }$ & $\sqrt{ }$ & $\sqrt{ }$ & $\sqrt{ }$ & & $\sqrt{ }$ & $\sqrt{ }$ & \\
\hline Dhiman (2012) & & $\sqrt{ }$ & $\sqrt{ }$ & & $\sqrt{ }$ & & & & $\sqrt{ }$ & \\
\hline Kalaivani et al. (2012) & $\sqrt{ }$ & & $\sqrt{ }$ & & $\sqrt{ }$ & & & $\sqrt{ }$ & $\sqrt{ }$ & $\sqrt{ }$ & \\
\hline Rahmah et al. (2011) & $\sqrt{ }$ & & $\sqrt{ }$ & & $\sqrt{ }$ & & $\sqrt{ }$ & $\sqrt{ }$ & $\sqrt{ }$ & $\sqrt{ }$ & $\sqrt{ }$ \\
\hline Wickramasinghe \& Perera (2010) & $\sqrt{ }$ & & $\sqrt{ }$ & $\sqrt{ }$ & & & $\sqrt{ }$ & & $\sqrt{ }$ & $\sqrt{ }$ \\
\hline Lin et al. (2010) & $\sqrt{ }$ & & $\sqrt{ }$ & $\sqrt{ }$ & $\sqrt{ }$ & $\sqrt{ }$ & $\sqrt{ }$ & & & $\sqrt{ }$ & $\sqrt{ }$ \\
\hline
\end{tabular}


Communication skills (CS). A total of 18 out of 21 studies focused on communication skills. Mohamad Shukri et al. (2014) defined communication skills as the skills that people use to communicate effectively with others. Kalaivani et al. (2012) listed oral communication and written communication as a subdomain for communication skill. Sivapalan et al. (2012) suggested communication skills comprise public relation and public speaking. While Jackson and Chapman (2012), recommended communication skills include verbal communication, giving and receiving feedback, public speaking, meeting participation and written communication.

Entrepreneurial skills (ES). A total of four studies reported entrepreneurial skills is one of the graduates' soft skills. Mohamad Shukri et al. (2014) defined entrepreneurial skills as the skills to explore an opportunity and create risk awareness, and to be creative and innovative in business or work. Roselina (2009) stated that entrepreneurial skills involve the ability to venture into business and work-related opportunities while creating risk awareness. This skill includes the ability to identify business opportunities and be able to prepare, build, and explore business plans.

Interpersonal skills (IS). Interpersonal skills featured the most often in the studies on graduates' soft skills from the perspective of Asian employers with a total of 19 studies. Abbasi et al. (2018) defined interpersonal skill as an ability to relate well, cooperate, empathise and work productively with people from a wide range of backgrounds. Jackson and Chapman (2012), suggested interpersonal skills comprise task collaboration, team working, social intelligence, cultural and diversity awareness, influencing others and conflict resolution while Kalaivani et al. (2012) listed respect of the other opinion and views, racial tolerance and conflict resolution as a subdomain for interpersonal skill.

Lifelong learning skills (LLS). A total of nine out of 21 studies concentrated on lifelong learning skills. Pang et al. (2019) defined lifelong learning skills as desire and aptitude for learning and learning as a basis for action. Roselina (2009) stated that in acquiring skills and knowledge, graduates should be able to do self-regulate learning independently. They should have the ability to search for relevant information from various sources and able to manage them efficiently. Graduates should also be receptive to new ideas and able to develop an inquiring mind.

Management skills (MS). A total of 12 studies found that management skill is one of the graduates' soft skills. Mohamad Shukri et al. (2014) defined management skills as the skills to effectively lead, supervise and manage projects or people. As stated by Mohamad Sattar et al. (2012), management skills comprise the ability to manage time, money, materials, facility resources, human resources and risks.

Numeracy skills (NS). Numeracy skills featured the least often in the studies on graduates' soft skills from the perspective of Asian employers with a total of three studies. Numeracy skills are the manipulation of numbers, general mathematical awareness and its application in practical contexts (Abbasi et al., 2018). A study by Sivapalan et al. (2012) found that the employers expect graduates to have adequate research skills to undertake basic survey as well as to analyse the data collected to furnish factual information spontaneously to stakeholders.

Problem solving skills (PSS). A total of 13 out of 21 studies focused on problem solving skills. Problem solving skills can be defined as an ability to undertake problem identification, apply problem-solving, formulations and solutions (Mohd Shamsuri \& Izaidin, 2014; Mohd Shamsuri et al., 2013). Abbasi et al. (2018) defined problem solving skills as coordinating all graduates know and can do, to bring about satisfactory outcomes. Jackson and Chapman (2012), recommended problem solving skills comprise reasoning, analysing and diagnosing and decision making.

Professional ethics and moral skills (PEMS). A total of four studies reported professional ethics and moral skills is one of the graduates' soft skills. Roselina (2009) defined professional ethics and moral skills as an ability to practice with high moral standards in the relevant professional practice. Beyond the working environment, graduates should be able to practice good ethics while having a sense of responsibility toward society.

Self-management skills (SMS). A total of 13 out of 21 studies concentrated on self-management skills. Abbasi et al. (2018) defined self-management skill as an ability of a graduate to accept responsibility, flexibility, improve own performance and time management. Jackson and Chapman (2012), suggested self-management skills comprise self-efficacy, stress tolerance, work-life balance and self-regulation.

Technological skills (TeS). A total of 10 studies found that technological skill is one of the graduates' soft skills. Abbasi et al. (2018) defined technological skill as an ability to use information and communication technology to access, process and create/provide information. Kalaivani et al. (2012) suggested technological skills comprise internet search and computer proficiency. A study by Sivapalan et al. (2012) found that the majority of the employers regarded technological skills as critical to organisational needs. In addition to basic knowledge in the use of software such as Word, Excel, and Access, they recommend that graduates must have adequate knowledge on statistical packages such as SPSS and mapping and spatial tools like GIS (Mapinfo) and Auto CAD.

Thinking skills (ThS). A total of 11 out of 21 studies focused on thinking skills. Mohamad Shukri et al. (2014) defined thinking skills as the skill to think critically, creatively, innovatively and analytically, and the ability to apply the knowledge in different contexts. While Pang et al. (2019) refer thinking skills as generates new ideas, 
inspirations, thinks outside of the box and a mindset for change. As stated by Triyono (2018), thinking skills are related to creative and innovative thinking, analysing, learning and giving feedback.

\section{Conclusions}

There is an increasing need for a better understanding of graduates' soft skills requirements with the increasing demands from employers. This study has attempted to systematically analyse the existing literature on graduates' soft skills from the perspective of Asian employers. The systematic review resulted in 11 major domains related to graduates' soft skills which are communication skills, entrepreneurial skills, interpersonal skills, lifelong learning skills, management skills, numeracy skills, problem solving skills, professional ethics and moral skills, self-management skills, technological skills and thinking skills. Higher education institutions need to work hard to develop or improve the graduates' soft skill to get them ready for the job place. The quality of graduates in the job place is more needed than the quantity. This study is important as it could assist the higher education institutions and students itself in preparing the students with appropriate soft skills to meet the requirement of the employers. It will also contribute to extending the literature by providing new findings of the graduates' soft skills from the perspective of Asian employers. However, this study does have some limitations. It does only classify the major domains of graduates' soft skills. A subdomain of graduates' soft skills is therefore desirable, taking into account the larger context nuance. It will also be necessary to replicate this study from the perspectives of the students or faculty members. What is more, if the research is needed to be generalised to any extent, the Asian region's limitations should be removed.

\section{REFERENCES}

[1] Abbasi, F.K., Ali, A., \& Bibi, N. (2018). Analysis of skill gap for business graduates: Managerial perspective from banking industry. Education and Training, 60(4), 354-367. doi: 10.1108/ET-08-2017-0120

[2] Amar Hisham Jaaffar, Hazril Izwar Ibrahim, Khairul Annuar Mohammad Shah, \& Abdul Hadi Zulkafli. (2016). Work-integrated learning and graduate employability skills: The employers' perspective. The Social Sciences, 11(21), 5270-5274. doi: 10.3923/sscience.2016.5270.5274

[3] Andrews, J., \& Higson, H. (2008). Graduate employability, 'soft skills' versus 'hard' business knowledge: A European study. Higher Education in Europe, 33(4), 411-422.

[4] Dhiman, M.C. (2012). Employers' perceptions about tourism management employability skills. Anatolia: An
International Journal of Tourism and Hospitality Research, 23(3), 359-372. doi: 10.1080/13032917.2012.711249

[5] Dunbar, K., Laing, G., \& Wynder, M. (2016). A content analysis of accounting job advertisements: Skill requirements for graduates. e-Journal of Business Education \& Scholarship of Teaching, 10(1), 58-72.

[6] Eğilmez, H.O., Engür1, D., \& Nalbantoğlu, E. (2019). Communication skills, self-esteem and attitude towards the music teaching of candidates studying in the TRNC. Universal Journal of Educational Research, 7(1), 190-197. doi: 10.13189/ujer.2019.070124

[7] Erlane K. Ghani, Rosdiana Rappa, \& Ardi Gunardi. (2018). Employers' perceived accounting graduates' soft skills. Academy of Accounting and Financial Studies Journal, 22(5), 1-11.

[8] Hayrol Azril Mohamed Shaffril, Krauss, S.E., \& Samsul Farid Samsuddin. (2018). A systematic review on Asian's farmers' adaptation practices towards climate change. Science of the Total Environment, 644, 683-695.

[9] Jackson, D., \& Chapman, E. (2012). Non-technical competencies in undergraduate business degree programs: Australian and UK perspectives. Studies in Higher Education, 37, 541-567.

[10] Jeong, Y-S., \& Sung, Y-H. (2019). The effect of network-based PUMA teaching-learning model on information literacy, computational thinking, and communication skills. Universal Journal of Educational Research, 7(5A), 103-113. doi: 10.13189/ujer.2019.071512

[11] Kahirol Mohd Salleh, Nur Izyan Subhi, Nor Lisa Sulaiman, \& Azmi Abdul Latif. (2016). Generic skills of technical undergraduates and industrial employers perceptions in Malaysia. International Journal of Applied Business and Economic Research, 14(14), 907-919.

[12] Kalaivani Nadarajah, Mahanem Mat Noor, Ainon Hamzah, \& Arina Anis Azlan. (2012). Employers perception on the quality of graduates from the School of Biosciences and Biotechnology, Universiti Kebangsaan Malaysia. The Social Sciences, 7(3), 478-485. doi: 10.3923/sscience.2012 .478 .485

[13] Khan, S. (2018). Demystifying the impact of university graduate's core competencies on work performance: A Saudi industrial perspective. International Journal of Engineering Business Management, 10, 1-10. doi: 10.1177 $/ 1847979018810043$

[14] Kostenkova, T.A., Pishchulin, V.N., \& Shepelev, M.I (2016). Interrelation of regional markets of labor and educational services: problems and prospects. International Journal of Economics and Financial, 6(2), 123-130.

[15] Lavy, I., \& Rashkovits, R. (2019). Engaging Information Systems students in a practicum-based project: Employers' perceptions and comparison. International Journal of Information and Communication Technology Education, 15(1), 67-82. doi: 10.4018/IJICTE.2019010105

[16] Lin, H.Y., Lin, S.H., Chiu, C.Y., Hung, W.T., \& Chen, C.Y. (2010). An AHP approach to industry-oriented management competence development in an institute of technology. World Transactions on Engineering and Technology Education, 8(3), 339-343. 
[17] Low, M., Botes, V., Rue, D.D., \& Allen, J. (2016). Accounting employers' expectations - the ideal accounting graduates. e-Journal of Business Education \& Scholarship of Teaching, 10(1), 36-57.

[18] Matsouka, K., \& Mihail, D.M. (2016). Graduates' employability: What do graduates and employers think? Industry and Higher Education, 30(5), 321-326.

[19] Mohamad Sattar Rasul, Rose Amnah Abd Rauf, Azlin Norhaini Mansor, \& Puvanasvaran, A.P. (2012). Employability skills assessment tool development. International Education Studies, 5(5), 43-56.

[20] Mohamad Shukri Abdul Hamid, Rafikul Islam, \& Noor Hazilah Abd Manaf. (2014). Employability skills development approaches: An application of the Analytic Network Process. Asian Academy of Management Journal, 19(1), 93-111.

[21] Mohd Shamsuri Md Saad, Anidah Robani, Zanariah Jano, \& Izaidin Ab. Majid. (2013). Employers' perception on engineering, information and communication technology (ICT) students' employability skills. Global Journal of Engineering Education, 15(1), 42-47.

[22] Mohd Shamsuri Md Saad, \& Izaidin Ab. Majid. (2014). Employers' perceptions of important employability skills required from Malaysian engineering and Information and Communication Technology (ICT) graduates. Global Journal of Engineering Education, 16(3), 110-115.

[23] Moher, D., Liberati, A., Tetzlaff, J., \& Altman, D.G., The PRISMA Group. (2009). Preferred reporting items for systematic reviews and meta-analyses: The PRISMA statement. PLoS Med. 6 (7), e1000097. doi: 10.1371/journal.pmed1000097.

[24] Natalia, C., Maria, S., Vladislav, S., \& Paquet, P. (2015). Problems of educational processes development and labor market needs analysis in Russia. Procedia - Social and Behavioral Sciences, 166, 309-316.

[25] Noor Azina Ismail. (2011). Graduates’ characteristics and unemployment: A study among Malaysian graduates. International Journal of Business and Social Sciences, 2(16), 94-102.

[26] Pang, E., Wong, M., Leung, C.H., \& Coombes, J. (2019). Competencies for fresh graduates' success at work: Perspectives of employers. Industry and Higher Education, 33(1), 55-65. doi: 10.1177/0950422218792333

[27] Radhakrishnan, M., \& Sudha, S. (2015). Analysis of employability skills of undergraduate engineering students in view of employers perspectives. ARPN Journal of Engineering and Applied Sciences, 10(20), 9304-9308.

[28] Rahmah Ismail, Ishak Yussof, \& Lai, W.S. (2011). Employers' perceptions on graduates in Malaysian services sector. International Business Management, 5(3), 184-193. doi: 10.3923/ibm.2011.184.193

[29] Rohani Salleh, Md Anwar Md Yusof, \& Mumtaz Ali Memon. (2016). Attributes of graduate architects: An industry perspective. The Social Sciences, 11(5), 551-556. doi: 10.3923/sscience.2016.551.556

[30] Roselina Shakir. (2009). Soft skills at the Malaysian institutes of higher learning. Asia Pacific Educ. Rev., 10,
309-315.

[31] Salina Daud, Noraina Mazuin Sapuan, Nurazariah Abidin, \& Jegatheesan Rajadurai. (2011a). Do business graduates' attributes fulfill industry requirements and expectations? Australian Journal of Basic and Applied Sciences, 5(9), 68-74.

[32] Salina Daud, Nurazariah Abidin, Noraina Mazuin Sapuan, \& Jegatheesan Rajadurai. (2011b). Enhancing university business curriculum using an Importance-Performance Approach: A case study of the business management faculty of a university in Malaysia. International Journal of Educational Management, 25(6), 545-569.

[33] Shiau, W.C., Ahmad, M.F., Izzuddin Zaman, \& Woan, S.K. (2018). Employers' perception on important employability skills in the manufacturing industry. International Journal of Engineering and Technology, 7(2), 170-175. doi: 10.14419/ijet.v7i2.29.13311

[34] Siti Zaidah Zainuddin, Pillai, S., Dumanig, F.P., \& Phillip, A. (2019). English language and graduate employability. Education and Training, 61(1), 79-93. doi: 10.1108/ET-06-2017-0089

[35] Sivapalan Selvadurai, Er, A.C., \& Marlyna Maros. (2012). Generic skills of prospective graduates from the employers' perspectives. Asian Social Science, 8(12), 295-303. doi:10.5539/ass.v8n12p295

[36] Stewart, C., Wall, A., \& Marciniec, S. (2016). Mixed signals: Do college graduates have the soft skills that employers want? Competition Forum, 14(2), 276-281.

[37] Ting, S.H., Ernisa Marzuki, Chuah, K.M., Misieng, J., \& Jerome, C. (2017). Employers' views on the importance of English proficiency and communication skill for employability in Malaysia. Indonesian Journal of Applied Linguistics, 7(2), 315-327. doi: 10.17509/ijal.v7i2.8132

[38] Triyono, M.B., Trianingsih, L., \& Nurhadi, D. (2018). Students' employability skills for construction drawing engineering in Indonesia. World Transactions on Engineering and Technology Education, 16(1), 29-35.

[39] Tsai, Y.H. (2017). Travel agency managers' perceptions of tourism industry employability. Journal of Hospitality, Leisure, Sport and Tourism, 20, 122-133. doi:10.1016/j.jhl ste.2017.04.001

[40] Wickramasinghe, V., \& Perera, L. (2010). Graduates', university lecturers' and employers' perceptions towards employability skills. Education and Training, 52(3), 226-244. doi: 10.1108/00400911011037355 